\title{
Measuring Performance of Nonprofit Organizations by Evaluating Integration of Their Values in the Project Management Process
}

\author{
Malika Souaf $^{1, *}$, Youssef El Wazani ${ }^{1}$, Mohammed Mouadili ${ }^{2}$ \\ ${ }^{1}$ Ecole Nationale de Commerce et de Gestion, Université Ibn Zohr, Agadir \\ ${ }^{2}$ Université Paris 13, Sorbonne Paris Cité, F-93430, Villetaneuse, France
}

Copyright () 2015 Horizon Research Publishing All rights reserved.

\begin{abstract}
The purpose of this paper is to identify how the integration of the human rights approaches in the projects management influences measuring performance of nonprofit organizations. This paper presents a case study of a network of nonprofit organizations operating throughout Morocco. Based on a qualitative approach, this study was conducted among 11 organizations, by using semi-structured interviews, questionnaires and focus groups. The results showed that the integration of the human rights approaches in the development of a new process of project management has a positive effect on the behavior of users, including managers and elected officials and also showed how the project results meet the goals and mission of nonprofit organizations. However, the study has also revealed the flipside of the medal expressed by the diversion of indicators, the complexity of projects evaluation using qualitative indicators and the perverse effects of measurement performance of nonprofit organizations. The results of this paper may serve as a roadmap for improved tools for evaluating projects based on the values of the organization and may guide the measurement performance of nonprofit organizations but must be conditioned by the specific context and priorities of stakeholder. The paper shows that measuring performance of nonprofit organizations comes back at first to evaluating the degree of integration of its values in their management system and the exercise of its vocation.
\end{abstract}

Keywords Measuring Performance, Human Rights, Values, Nonprofit Organization, Case Studies, Morocco

\section{Introduction}

Nonprofit organizations or the third sector have experienced unprecedented growth in recent years. Thus, we have witnessed a proliferation of projects and development of programs to support the efforts of civil society in the different fields of actions for social development.

The growth of the third sector has changed the context of action of nonprofit organizations and has set new conditions and constraints for policy makers in these organizations. Indeed, the non-profit organizations are facing an increasing competition [1-4] of a number of agencies that proliferate, all competing to find scarce funding from donors, foundations, and government. In addition, donors have become increasingly demanding in terms of accountability as well as members of nonprofit organizations. These must therefore provide accurate and relevant information not only on the finances of the organization but also on realization of their mission.

For Kaplan [4], managers and leaders of nonprofit organizations are increasingly concerned with the measurement and management of organizational performance. Financial measures alone, or even supplemented by a collection of ad hoc non-financial tools, are not sufficient to motivate and evaluate the achievements of the mission.

The nonprofit organizations advocating the defense of universal values are more affected than others, and must demonstrate that they are consistent with their values. However, measuring performance of nonprofit organizations and the assessment of the completion of their mission is not an easy thing. Therefore the question that arises is how to measure the performance of these organizations in order to attest the well-founded of their actions.

The present paper tries to provide some answers through a case study that was conducted with nonprofit organizations in Morocco. The objective of this study was to develop a system for the identification, planning, management, monitoring and evaluation of projects and programs incorporating the values of the organization mainly the gender approach, human-rights and participatory approaches. 


\section{Theoretical Framework}

Understanding the difficulty of measuring performance in nonprofit organizations comes to understand the complexity of the management system of these organizations. Indeed, more than ever, nonprofit organizations have to develop their own management tools that meet their specific needs and characteristics. The concern also of several actors in the field, researchers and practitioners is to bring management methods appropriate to NPOs.

Nevertheless, the nonprofit organizations today face a major challenge: how to remain faithful to their mission while innovating in the way they act. Indeed, several authors note that the fact that nonprofit organizations adopt tools and techniques of private management can influence and distract them from their social vocation. Avare and Sponem [5] wondered if too much management would not lead to kill the social.

Bush [6] argues that: "the emphasis on private sector philosophy and technique that is increasing within the sector may, in my experience, lead to a disengagement from mission as the primary focus of nonprofit activity and for evaluation of a nonprofit's accomplishments." Bainard and Simplon [7] for their part, based on Bush's findings [6], state that "one of the biggest challenges facing organizations in the sector was how to retain their "nonprofit spirit in a for profit world".

In this context, and as it is the case in our study, we can ask whether a tool like the balanced scorecard developed for the needs of for-profit organization can be adapted for measuring performance of nonprofit one.

We can then ask: what are the conditions for the exercise of measuring performance in nonprofit organizations and what underlies the idea of the need of a new approach for measuring performance other than balanced scorecard?

Value and mission of nonprofit organization as measurement framework

Dike [8] argued that there is "one way of understanding a nonprofit organization is to observe the goals or ends to which it aspires. This is found in its mission statement, which outlines its purpose."

However, experience and field's observation shows that many of the problems that nonprofit organizations have experienced are due to the fact that they are diverted from their mission. Indeed, the issue of financial dependence grows the nonprofit organizations whose contributions members were insufficient to seek money where it is: state subsidies, cooperation and aid donors. However, the use of such external financing implies for nonprofit organizations, at first, acceptance of financing conditions [3], and secondly the launch of projects that do not necessarily correspond to the object of the organization or to its core mission.

This mode of action has developed in the nonprofit organizations a project culture and made them more reactive rather than active. In other words, nonprofit organizations focus on looking for any funding opportunity that will ensure the survival of the organization via the setting up of projects not necessarily important, and in some cases unnecessary. Therefore, they are committed in thoughtless projects, not or poorly planned and have been undergo the will of others rather than to be agents of social change [2].

Herman and Heimovics [9] advocated: "The choice of a mission for an organization depends on the potential for the acquisition of sufficient resources to carry out that mission. Conversely, the acquisition of certain kinds of resources can influence the mission an organization chooses to undertake. Any mission, no matter how great the cause, is likely to fail if the organization lacks necessary and sufficient resources to pursue it. Moreover, decisions about strategies for acquiring resources must be consistent with the mission and ethical values of the organization. Actions in one realm affect the other realms. The leadership challenge is to see that decisions and actions in one realm are not only consistent with those in other realms but also mutually reinforcing."

But what differentiates nonprofit organizations from private organizations and public agencies is the predominance of ethical and moral values. For several authors in the field [1, $10-13]$ nonprofit organizations are entities who are engaged in a moral contract with the public with guarantees of good intentions and integrity, without which they have no reason to exist or to exercise. Thus, the first question of this case study is how to ensure that nonprofit organizations engage only in projects that reflect their own image and their purpose?

\section{Project Management and Measuring Performance of Nonprofit organization}

Performance measurement of nonprofit organizations is a sensitive issue and has no consensus. Worth explains: "if doing the right things does not guarantee that the organization is effective in achieving its mission, then we need some tools to evaluate results."

Indeed, for nonprofit organizations, it is not a question of profitability measure or an economic productivity of these organizations, but the degree of achievement of their missions. Authors in the field distinguish the performance, effectiveness, and efficiency $[1,14]$. Thus, the performance is measured in terms of the achievement of the organizational mission. The effectiveness measures the achievement of results achieved against agreed outcomes. The efficiency for its part assesses the resources used in relation to outputs obtained. Worth precise: "being effective may be necessary to being high performing, but it not necessarily sufficient."

Although most of the activity of nonprofit organizations is based on programs and projects, their performance cannot be reduced to the implementation of these programs or their completion but their overall contribution to the achievement of the mission of the organization and its being reason. Also, the greatest difficulty in measuring projects performance is the measure of their impact and long-term effects. Worth emphasizes that "... managers of nonprofit organizations must measure their success by a double bottom line. A 
nonprofit exists to pursue a social mission, and success must be measured in terms of its ability to achieve that mission."

To evaluate the performance, the authors identified the following tools: financial ratios, sector index or measuring against peers, the index of mission or measuring against mission, program outcomes, balanced scorecard [15], social return on investment, blended value.

For the index of mission, donors and funders interested closer to them because it reflects the sincerity of the organization and justify its existence. However, it is important to note that the problem of this measure is its volatility and qualitative criteria. Worth argued: «one obstacle to measuring success in accomplishing the mission is the loftiness and vagueness of many mission statements." Which brings us to a third question: how to integrate the values and mission in measuring the performance of nonprofit organizations?

\section{What tool to measure what?}

Balanced Scorecard was developed by Kaplan and Norton [16] in view of the needs of organizations in the field of measuring performance by including non-financial criteria in the core of the measure. However, despite its considerable contribution, Balanced Scorecard has been the subject of several critical limiting its use as an indispensable tool in measuring performance especially in the third sector.

Indeed, the Balanced Scorecard [17-18] does not include the external environment as an important dimension affecting the performance of the company. In addition, Kaplan \& Norton (2001) advocates the use of limited indicators in performance measurement. That makes it an inadequate tool to measure the performance of nonprofit organization based on evaluating the impact of their action and the achievement of their mission. In fact, the establishment of evidence of impact requires extensive analysis involving several indicators especially in an uncertain environment such as the treatment of social problems [2].

For its part, Ebrahim [2] tried, through his research, to examine how social sector organizations - such as nonprofit organizations and social enterprises - can measure their performance in order to obtain best results. His work focuses on organizations fighting against poverty, ranging from large international non-governmental organizations (NGOs) to local organizations. His research has focused on how managers and board members can identify the most important measurement methods to implement and what are the abilities, skills and support systems they need to build a measurement tool, and most importantly, how they can use this information to define strategy and achieve their missions.

For Ebrahim [2], the tool must be used to determine what kinds of measures would be appropriate, as dictated by the mission and goals of the organization. To do this, he proposed a logical framework for the construction of the measure based on the consideration of the following questions:
- What can the organization reasonably measure in the logical chain: inputs, activities, outputs, outcomes or impacts?

- What is the organization needs to measure for reporting to donors?

- How to make the measure use helpful for the organization to better accomplish its mission?

$\mathrm{He}$ also proposed, based on the theory of change, to explore how the relationship between cause and effect of an intervention is interpreted and how managers of nonprofit organization exercise control over their actions and the results achieved?

It is in this framework of analysis developed by Ebrahim [2] and considering the limits of Balanced Scorecard, that we started our case study. We tried to develop a logic schema tool for measuring performance to meet the expectations of different stakeholders including donors seeking to know where and how their money was spent.

\section{The Empirical Context}

Giving a common definition to nonprofit organizations is a difficult thing. As emphasized by Worth [1], "the nonprofit sector is so diverse and its structure is so complex." But regardless of the sector in which they operate (education, health, social, culture ...) or their status, the nonprofit organizations are supposed to serve the common interest and respond to human needs of their members and target population $[19,20]$.

Nonprofit organizations differ from government agencies in the sense that they are based on voluntary action and from for-profit entities in the private sector in that the nonprofit organizations don't distribute a profit [12]. Worth [1] states that "the term nonprofit organization really refers to one thing nonprofit organizations do not do".

In most countries, nonprofit organizations came to take over where the governments have failed; it is particularly the case in developing countries and Morocco doesn't make exception to this rule. Nonprofit organizations in Morocco are governed by the $1958^{\text {th }}$ Act that covers diverse types of nonprofit organizations with different interests: political, syndical, philanthropic, development, cultural... But the most dominant nonprofit organizations are those working in development area.

According to the Moroccan Ministry of Social Development [21], the sector of nonprofit organizations has experienced unprecedented growth during the last decade due to changes in policy of authorities since 1995 through the microfinance policy at first, and second, by the launch of the National Initiative for Human Development (INDH) in 2005. This policy aims to ensure that nonprofit organizations support government in the fight against poverty and precariousness.

Actually, we count over than 30000 nonprofit organizations in morocco. However, this figure only informs about raw creations but there are no data on the organizations 
that are really active.

\section{The Research Methodology}

As stated in the theoretical part, measuring performance of nonprofit organization must be done through the evaluation of the integration of their values in the exercise of their activity and by measuring the achievement of their mission. In our case, the organizations involved in this study operate in the field of development with an ultimate goal of making changes to the culture of the people they serve. This change is required by the commitments and by a moral contract with stakeholders. It is also a requirement of the donors who have become more demanding in this respect in order to finance project.

Indeed, if governments and donors seeking to improve the living conditions of the population, especially vulnerable groups, they are seeking a long-term change in mindsets and attitudes of population. Among the aspirations enshrined in the Millennium Goals of the United Nations, we retain for Morocco: gender equality and the promotion of human rights.

For Rocher [22] social change is "all observable and verifiable changes over time that affect, in a way that is not temporary, a structure or functioning of a community and that alter the course of its history."

To talk about social change, it must meet the follo wing conditions:

- Social change is necessarily a collective phenomenon, which involves a community and affects the conditions or lifestyles.

- Social change involves a structural change, thus changing the state of social organization in whole or in part.

- A change in structure must be identified in time and must measure in a space-time, the difference with an initial situation of reference.

- Finally, social change must be sustainable and permanent.

Henceforth, the performance of the nonprofit organizations involved in this study will be considered in relation to their degree of assimilation and appropriation of human rights approach, gender approach and participatory approach. To achieve this we have tried to follow the analytical framework of Ebrahim [2] on the measurement process and approaches that we formulated according to Figure 1.

In this sense, our study focuses only on organizations who worked in development area with a clear level of organization and structure [1]. These organizations are structured in a network called Associative Space compound of 61 members with a large coverage of all the Moroccan territory. As it was indicated in their status this network founded in 1996 is a Moroccan Association helping to strengthen and promote the movement for democratic development by developing the skills and abilities of associative frameworks, and improving the environment for the action of their members.

This research project began in December 2008 and was completed in late 2011. Its main idea was to set up a specification for the creation of an information system for planning, managing, monitoring, evaluating and controlling of projects and programs. It contained two parts: the first concerns the definition of tools and the development of indicators and the second part concerns the implementation of the information system for using of tools and indicators. Our study is limited to the first component only.

\section{Case selection}

The case studied here concern 11 nonprofit organizations member of the network "Associative Space". Although the network is composed of 61 associations, it was deemed necessary to begin by the 11 organizations across the Moroccan territory as a pilot experience before dissemination to to the other associations. The criteria considered for selecting the case study are:

1) The nonprofit relevant organizations have worked for promoting human rights, participatory and gender approaches's in society.

2) The resource persons representing the cases who may participate in the study and limited to two persons are the president and the treasurer. The selected persons were choosen considering there responsiblity in the organization and because they ensure effective monitoring of projects and are accountable to General Assembly (1958 Act).

3) The degree of control of resource persons of the traditional tools for editing, management and evaluation of projects.

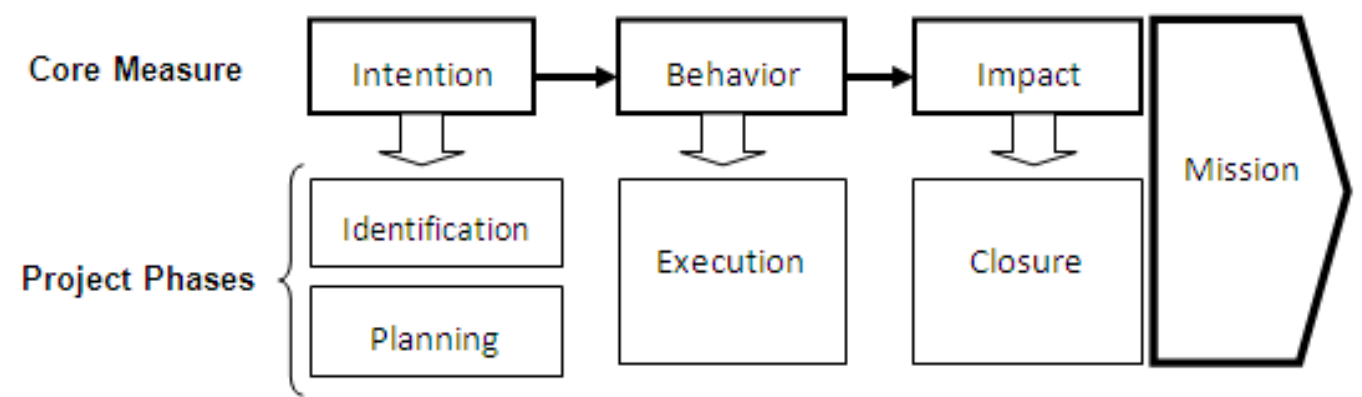

Figure 1. Measuring Process 


\section{Collection of data}

The study began in December 2008 with all resource persons that are involved in the project and was conducted by three researchers. At first, it was set, with the network administration, work methodology. Thereby, we have agreed on the phases of the study, meeting dates and the various key people for the project. The works carried out to complete the study were as follows:

1) Documentary research: The research team has analyzed all documents relating to the case study, the history and the work tools of the network. This step was useful in the sense that it should prevent the degree of mastery of the research subject the whole techniques of project management. It was also interesting to determine what kind of monitoring and evaluation methods were in place.

2) Semi-structured interviews: Several semi-structured interviews were conducted at several levels. Initially with the network managers in order to clarify the strengths and weaknesses in their project management. Then, the elected persons of the network to understand on the overall strategy and mission of the organization and its expectations. A regular donor of the network was also involved to reconsider its vision and perception of the evaluation.

3) Questionnaires: Questionnaires were sent to representatives of various organizations before each meeting to prepare the focus-groups and know the difficulties encountered when handling project forms.

4) Focus groups: several focus groups were held at each end of the stage with the 11 selected organizations. Focus groups are organized around the following themes:

- Difficulties, expectations and perception of traditional norms of project management. In this section, participants expressed the difficulties and weaknesses experienced in relation to certain methods of monitoring and evaluation project performed including Results Based Management.

- Integration of the gender approach, participatory and human rights approaches in the process of identification, planning, managing, monitoring and evaluation of projects and programs. There was a focus-group of restitution on how to consider these approaches in the daily work.

- Feedback on the new tools developed for the identification, planning, monitoring and evaluation of projects and programs.

Materials used in the conduct of the study were handled in the following manner (Table 1.):

1) Semi-structured interviews:

- $\quad 07$ semi-structured interviews with responsible at the central level that is to say, the network including members of the board of directors and management staff.
- 22 interviews with leaders of nonprofit organizations network members involved in the study.

- 01 interview with the donor representative.

2) Questionnaires: 33 questionnaires were administered to managers of nonprofit organizations participating in the study and before the organization of each focus group. The questionnaire involves the response of president and treasurer of each organization. All questionnaires were received saw that there was a moral obligation for organizations participating as members of the network.

3) Focus group : 03 focus group led by the participants with the participation of all those interviewed. The first focus group consisted of a diagnosis of participants' skills in project management and evaluation of expectations. The second focus group is organized around the handling of project management tools and organizations perception of the assessment. The latter focus group concerned the exercise of the integration of gender approaches, participatory and human rights in the process of project management.

4) A final workshop was finally performed to validate the results and make corrections to the measurement models proposed.

Table 1. Number of interviews and the interviewees' positions

\begin{tabular}{|c|c|c|c|c|}
\hline & \multicolumn{2}{|c|}{ Profil } & $\begin{array}{c}\text { Total } \\
\text { interviews }\end{array}$ & $\begin{array}{l}\text { Focus } \\
\text { Group }\end{array}$ \\
\hline \multirow{5}{*}{$\begin{array}{c}\text { NPO } \\
\text { Network }\end{array}$} & \multicolumn{2}{|c|}{ President } & 1 & \\
\hline & \multicolumn{2}{|c|}{ Members of the board } & 2 & \\
\hline & \multirow{3}{*}{ Managers } & Director & 1 & \\
\hline & & $\begin{array}{c}\text { Programme } \\
\text { officer }\end{array}$ & 02 & \\
\hline & & $\begin{array}{l}\text { information } \\
\text { system } \\
\text { Director } \\
\end{array}$ & 01 & 3 \\
\hline \multirow{2}{*}{ NPO } & \multicolumn{2}{|c|}{ President } & 11 & \\
\hline & \multicolumn{2}{|c|}{ Treasurer } & 11 & \\
\hline \multicolumn{3}{|c|}{ Donor } & 01 & \\
\hline \multicolumn{3}{|c|}{ Total } & 30 & \\
\hline
\end{tabular}

\section{Analysis of data}

The first step in the analysis of internal working documents of the network was accompanied in parallel by a literature review of experiences of gender approaches, participatory and human rights as well as research on standards and standards of evaluation of these approaches including those adopted by the United Nations and the European Commission. Indeed, it was first necessary to work on a global reference in the field of human rights. Then it came to look at the working methods of the different donors as models of planning, managing and evaluation of projects such as UNDP, European Commission, and USAID. These donors had their own grids and forms of planning, monitoring and evaluation of projects that nonprofit 
organizations should follow each they apply for funding for one of them.

The phase of document analysis allowed us to orient our work with organizations participating to the study by providing a model base for planning. This also led to direct interventions on the issue of approaches with reference to international standards.

Focus groups, in turn, were used to test the proposed models and rectify problems or issues non-adapted to organizations.

\section{State of the art}

The traditional method of nonprofit organizations in accordance with the donors was based on the techniques of project management in all organizations. The evaluation was initially based on the principle of management by objectives which then gave way to managing for results.

Refering to the definition of the UNDP the results-based management is : "a strategy or management method applied by an organization to ensure that its processes, products and services contribute to the achievement of clearly defined outcomes. Results-based management provides a coherent framework for strategic planning and management by improving learning and accountability. It is also a broad management strategy aimed at making significant changes in the way agencies operate, with an emphasis on improving performance and achieving results. This requires the definition of realistic results, monitoring progress in achieving the expected results, integrating lessons learned into management decisions and reporting of information about the performance. "In other words, management process is based on a result of some inputs (resources and activities), and monitoring and evaluation is done on this sense.

This method has, however, limitations that make it inadequate for measuring performance. In these limits we retain, in the one hand, the difficulty in defining results, and secondly, the difficulty of establishing the relationship of cause and effect to measure the impact. In addition, to measure the performance of nonprofit organizations, results-based management show processes and actions in relation to data, but does not account for the correlation between the results and mission of organization. In other words, having as a result the delivery of training on human rights does not mean that the mission of changing habits was completed.

Therefore, the study focused on the following two points:

1) Assessment of the strengths and weaknesses of the traditional processes of identification, planning, managing, monitoring and evaluation of projects and programs including the management based on results.

2) Proposal and test of a new method incorporating gender approaches, participatory and human rights in the process of identification, planning, managing, monitoring and evaluation of projects and programs.

We have to note that in the context of this study, the research team had to demonstrate the integration of approaches in the course of his work especially the gender approach and participatory.

\section{Results}

The following section presents the finding from the case study.

The study was conducted among 11 nonprofit organizations with the participation of the Executive Board of the network, elected persons of the network and donor representatives. Participating organizations are associations working in the field of development oriented towards improving the living conditions of the rural population, the situation of women, children and the defense of universal rights. They cover a geographic rather complete of Morocco with its different ethnic and socioeconomic groups. The network headquarters is based at the capital Rabat. The Presidency and the Council of the Network is composed of representatives of member organizations but the presidency is generally attributed to a person living in Rabat for reasons of proximity to centers of political decisions and easy access to information.

\section{Practice of Project management}

Selected organizations in the study are used to work on projects funded by various donors including: USAID, United Nations programs, the European Commission as well as state subsidies. However, the majority of the shares of the participating organizations pass through the network who postulate on behalf of the collective. This allows to the network to attract more funds and to centralize management of projects and programs. This situation is the result of a policy initiated by the donors whom, within the framework of calls for projects, suggest the constitution of consortium of partners.

The historical shows that the regular work with funders has begotten a certain custom in the work of these organizations and network in particular, especially the practice of management based on results. Management based on results involves a definition of outputs to achieve through the engagement of one or more activities. This method then allows the measurement of success of a project or program through the results assessment.

The traditional project management process in these organizations is composed of the following phases:

1) Identification of the Project leader and manager

2) Purpose and specific objectives

3) Description of project: initial situation, needs and expectations

4) Expected Results

5) Activities to be undertaken to achieve the results

6) Requested Budget

Overall, calls to project require the definition of a set of indicators including indicators of progress and achievements 
or performance indicators but also hypotheses of risks. The projects cover an average periods ranging from one to three years. The literature review and interviews showed that the common definition among users of an indicator is the SMART one (Specific, Measurable, Achievable, Reasonable, And Temporal).

Bauer [23] defines indicators as "statistics, time series, and any other kind of empirical evidence that allow us to assess where we are and where we are going with respect to our values and goals." Sutter [24], meanwhile, wonders about the types of indicators to choose, is it objective indicators of living conditions or subjective indicators of perception and appreciation of individual conditions life?

\section{Promoting values of nonprofit organizations}

Organizations and the network, as indicated by their statutes, are working for a social change. With the help of donors, they participate in all activities and actions for the promotion of human rights, gender equality and public participation in decision making [25]. These areas form the basis of the values of non-profit organizations and their being reason. The projects undertaken by the network and its members are the means to promote these values and contribute to the achievement of their mission. However, projects and programs do not explicitly state that their objective is to improve the status of women. Thus, a project can be designed to have as an objective to make the school accessible to girls in a remote village. But, as a product it describes just the building of a school while the result will be the enrollment of girls.

The nonprofit organizations in carrying out their mission, try to conform to universal values defined by the various charters including the United Nations charter for Human Rights [26, 27]. They adopt these standards as repositories that allow them to guide their actions as a civil society. The known best charters are:

- Convention on the Elimination of All Forms of Discrimination against Women (CEDAW),

- Millenium Declaration and Millenium Development Goals

In addition, donors, in a spirit of increasing accountability require knowing the fate of their money, not just how it was spent, but also how it was used [28, 29].

\section{What has been measured?}

In light of these clarifications, we in this study worked on measuring performance by focusing on the question of the extent of change. Thus, it was a question of how to measure the difference between the initial situation and the actual one and to evaluate the change that the integration of gender approach, participatory approach and human rights approach has brought. At the operational level, we have built a form containing all issues about proposed approaches to measure quantitatively and qualitatively the change. These questions concern all stages of project management from identification to evaluation. Indeed, the measurement keys should inform us at every phase of the programs on the inclusion of values of the organization.

Measurement indicators were also included in the project budget and we integrate questions about budget allocation and how the budget contributes to the achievement of the mission and the realization of values. For example, we integrated the concept of budget sensitive to gender that we have applied to the others approaches, namely participatory and human rights.

\section{Discussion}

Despite their familiarity with project management, nonprofit organizations showed some weakness and gaps in the integration of the concept of evaluation in their way of working. At such level of skills, measuring performance of these organizations is far from a given.

\section{Project management level}

First, organizations have shown difficulties in handling of forms requested by donors. Indeed, while the asked information is basic, the problem does not arise, but once clarifications and details are requested, the interlocutors begin to have complications. This is partly explained by the fact that those responsible for these organizations are generally non specialists in management and project management. In addition, a part of the study was to put the participants from the other side of the fence and play the role of donors to understand their expectations and how they practice the evaluation.

Second, participants are struggling to identify and formulate appropriate indicators for monitoring and evaluation of projects. The selection and definition of the indicator remains delicate point raised by all participants.

Thus, confusion was found between the different progress indicators, processes indicators and outcomes indicators. Indicators are also far from SMART because participants can not set benchmarks to measure the effectiveness of their action and is limited to gross percentages. For the education of girls indicator for example, a rate of $80 \%$ of girls that were enrolled is formulated. This percentage, in terms of efficiency, is meaningless if it is not reported as a reference to the target population, or dropout rate.

Considering these shortcomings, the first work was done in the direction of facilitate the handling of editing tools and project management according to current standards before starting the step of integration of approaches in the process.

Third, it was noted an omission of identification phase in the process of project management. Also, exercise has been done in this direction to explain the origin of the project and its idea. It is not enough to express the needs, but it was necessary to sensitize participants of the importance of how the need was felt and how the project idea was expressed. This was important to allow the continuation of the study especially in the part of participative approach.

Measuring performance level 
Once the participants have mastered the techniques for identifying, planning, monitoring and evaluation of projects, the second phase was discussed namely the integration of approaches in the process of project management.

Indeed, the measuring performance of nonprofit organizations comes through measuring the degree of fulfillment of their mission. However, the mission of these organizations is a daily exercie and is carried by the projects and programs they undertake. For the case studied here, as stipulated by Colin, the mission of these organizations was the promotion of gender equality, the participation of the population in the decision-making and enjoying their human right. It was then necessary to develop tools for theoretical measure and to force their practice.

To achieve this, participants were asked to each phase of the project to answer questions or provide indicators for integrated approaches gender, human rights and participatory. Figure 1 summarizes the overall vision of the process of monitoring and evaluation of integrated approaches and Table 2 is shown the measuring process in each level of the project to measure the consideration of approaches and values.

Table 2. Measuring process of integration of gender, participatory and human rights approaches in project management.

\begin{tabular}{|c|c|}
\hline & Intention \\
\hline $\begin{array}{l}\text { What to } \\
\text { measure }\end{array}$ & $\begin{array}{l}\text { - How the idea of project was developed? } \\
\text { - How Women took part to the formulation of the } \\
\text { project idea? } \\
\text { How the whole population took part the } \\
\text { formulation of the project idea? } \\
\text { Did the project shown the role of stakeholders in } \\
\text { project planning? } \\
\text { - Who took part to project planning? } \\
\text { How project was planned? }\end{array}$ \\
\hline
\end{tabular}

\begin{tabular}{|c|ll|}
\hline & \multicolumn{1}{c|}{ Behavior } \\
\hline & $-\quad \begin{array}{l}\text { Who took part to project planning? } \\
\text { What to } \\
\text { measure }\end{array}$ & $\begin{array}{l}\text { Who participate to the project execution? } \\
\text { Did the project shown the role of stakeholders in } \\
\text { project execution? }\end{array}$ \\
& $\begin{array}{l}\text { Did the project planning shown the benefit of } \\
\text { stakeholders? }\end{array}$ \\
\hline
\end{tabular}

\begin{tabular}{|c|ll|}
\hline & \multicolumn{1}{c|}{ Impact } \\
\hline $\begin{array}{l}\text { What to } \\
\text { measure }\end{array}$ & - & $\begin{array}{l}\text { What is the benefit of project for stakeholders? } \\
\text { What change project make to the initial situation? }\end{array}$ \\
& $\begin{array}{l}\text { What have been changed in the population habit } \\
\text { and attitude. }\end{array}$ \\
\hline
\end{tabular}

The performance measurement model that we developed is based on the principle of the evaluation of the achievement of mission by evaluating the integration of values in the activities of the organization including the management process of a project. This led us to focus on three levels of analysis: study of intent, behavior study and impact study.

Study of intent: At this level the goal is to prove that the nonprofit organization has always had good intentions and that his behavior or his interest for the field of activity is not only an opportunism act. It is demonstrated that the actions envisaged in the framework of a project or program is the result of a felt need above all by the target population and that the approach used is participatory and democratic and does not undermine in any way the stakeholders' right. The measurement of this dimension is done at the stage of project identification and editing.

Study of Behavior: It's a dimension of assessment of the concordance of tools deployed and planned actions with the values of the organization. This will prevent that the nonprofit organizations fall into the principle that the end justifies the means. Indeed, it must be ensured that for every good purpose it is necessary that the means used and attitudes reflect that the organization is acting in the right sense of its mission. This step aims to verify compliance by the organization of its commitments expressed in the phase of intention or identification.

Impact assessment: The impact, more than the outcome, is measured by the change in the population attitudes and behaviors. Often based on qualitative indicators, the impact takes longer to perform and to come out with concrete results.

The objective of this manipulation is not only to measure the integration of approaches, but also to bring the participant organizations to live the values they defend and to exercise them. Thus, organizations will move from a management based on results to a management based on values. Therefore, for each project or program, network organizations will be forced to give answers on the quantitative and qualitative participation of women in the formulation of the project idea. They will have to explain what are the part of women and the other categories of population in the project in terms of budget and responsibility and how they participate in the exercise of their right of decision. Same for the target population, nonprofit organizations must demonstrate how it has contributed to the formulation of the project and how it was directly affected.

This approach has shifted the work of associations from a simple culture of project based more on budget management to a focusing on the values and mission. This will allow, first, to meet the needs of accountability to donors, and secondly to facilitate the measurement of performance of nonprofit organizations.

\section{Conclusions}

Measuring performance of nonprofit organizations is a difficult task. Indeed, the problem is not there to evaluate the profitability of financial assets or productivity of a production line but to measure the social value of the work done by nonprofit organizations. This social utility cannot be measured at a given time and is influenced by changes in society in the long term permanently [22]. However, the current challenge for nonprofit organizations is to measure 
and demonstrate the impact of their actions.

However, the pressing demands of donors and the development of the concept of accountability certainly oblige nonprofit organizations to develop techniques to prove the good sense of their actions and provide the certificate of fidelity to their mission. Moreover, the use of certain biggest nonprofit organizations of tools such as the balanced scorecard in their management system is a manifestation of awareness of what is measuring performance and their importance for the organization success and its survival $[1-2,15]$.

\section{Diversion of sense}

The use of performance measurement of nonprofit organizations through the evaluation of the integration of their values in their conduct and exercise of their activity will push them to comply with their duties. However, this will not eliminate the dominance of the crop and the use of project funds to survive at the expense of mission priorities. Worse, there is a risk of diversion of the meaning of the concept of measuring of social performance by changing the sense of indicators.

Indeed, one indicator is not enough to assess the quality of the actions taken and results achieved. As indicated by Trosa and Bartoli [30]: "the numbers never speak for themselves and the quantitative does not summarize the public services because indicators can be interpreted differently and the sense could be hijacked."

However, in our research, it was shown that to implement of an evaluation system, at least at the identification phase, would give rise to strategic behavior level of nonprofit organizations. This will make the difference between for-profit organizations that have used the slogan of the corporate social responsibility for marketing purposes.

\section{Missing standards}

Define the purpose of an indicator is more difficult than its quantification. In our case study, each donor identified a non-exhaustive list of indicators but the assessment of these indicators is subjective and depends on the person who provided the measure. Also, the most relevant indicators remain qualitative and still in their verification based on the concrete observation of the ground.

In addition to the qualitative character, indicators of measuring performance do not provide the same direction from one project to another and from one situation to another [24]. The enrollment of women do not have the same weight in rural than the urban areas.

Finally, we can say that measuring performance of nonprofit organizations still difficult to do regarding the complexity of the third sector. It actually depends on the size of the organization and its experience in managing projects and programs. More the organization is small, more the means are lacking. However, despite the shortcomings that may be encountered in the context of the definition of performance indicators, the fact of requiring from nonprofit organizations to show the merits of their actions is very useful. In fact, it allows to donors to ensure where funds they grant are used, to strengthen the confidence of the organization members in it and to its directors and managers to dispose on a strategic management tool.

\section{REFERENCES}

[1] Worth, M. (2009), Nonprofit management: principles and practice, Sage publications, California.

[2] Ebrahim, A. (2010), "The Many Faces of Nonprofit Accountability." Harvard Business School Working Paper, No. 10-069, February.

[3] Van Til, J. (2011), Classic thought leaders framing U.S. philanthropy, in Agard, K., Leadership in nonprofit organizations, Sage publications, California, p. 87 - 95.

[4] Kaplan, R. S. (2002). The balanced scorecard and nonprofit organizations. Harvard Business School Publishing.

[5] Avare, Ph. \& Sponem S. (2010), "Le managérialisme et les associations" (Managerialism and associations) in in Hoarau, C. \& Laville, J-L (Eds), La gouvernance des associations (Gouvernance of associations), Eres édition, Paris, p. 113-130.

[6] Bush, R. (1992). Survival of the nonprofit spirit in a for-profit world. Nonprofit and Voluntary Sector Quarterly, 21, p. 391-410.

[7] Brainard, L-A. \& Siplon, P-D., Toward Nonprofit Organization Reform in the Voluntary Spirit: Lessons From the Internet, Nonprofit and Voluntary Sector Quarterly, vol. 33, no. 3, September 2004 435-457.

[8] DICKE, L. (2011), A nonprofit organization, in Agard, K., Leadership in nonprofit organizations, Sage publications, California, p. 29 - 37.

[9] Herman, R. D. \& Heimovics, D. (2005), Executive Leadership. in R. D. Herman (Ed), The Jossey-Bass Handbook of Nonprofit Leadership and Management (2nd Edition). San Francisco: Jossey-Bass.

[10] Jeavons, T. (2005), Ethical Nonprofit Management. in R. D. Herman (Ed), The Jossey-Bass Handbook of Nonprofit Leadership and Management. San Francisco: Jossey-Bass.

[11] Van Til, J. (2000).Growing civil society: From nonprofit sector to third space. Bloomington: Indiana University Press.

[12] Powell W. and Steinberg, R. (2006), The nonprofit sector, Yale University Press, London.

[13] Oster, S-M. (1995), Strategic Management for Nonprofit Organizations: Theory and Cases, Oxford University Press.

[14] Kanter, R. \& Summers, D. (2001), Doing well while doing good: Dilemmas of performance measurement in Nonprofit organizations and the need for a multiple-constituency approach, in McKevitt, D \& Lawto A (Eds), Public Sector Management: Theory, Critique and Practice, Sage Publications, p. 220-237.

[15] KAPLAN Robert S., Strategic Performance Measurement and Management in Nonprofit Organizations, Nonprofit 
Management \& Leadership, 11(3), Spring 2001, p. 353-370.

[16] Kaplan, R. S., Norton, D. P., \& Horv6th, P. (1996). The balanced scorecard, (Vol. 6). Boston: Harvard Business School Press.

[17] Atkinson, A. A., Balakrishnan, R., Booth, P., Cote, J. M., Groot, T., Malmi, T., \& Wu, A. (1997). New directions in management accounting research.Journal of Management Accounting Research, 9, 79-108.

[18] Oyon D. et Mooraj S. (1998), «Das "Balanced Scorecard". Mode oder Wertschöpfung »,Der Treuhaender, p. 67-98.

[19] Laville, J-L. \& Sainsaulieu, R. (1997), Sociologie de l'association, Desclée de Brouwer, Paris, 1997.

[20] Van Til, J. (1990). Critical issues in American philanthropy: Strengthening theory and practice. San Francisco: Jossey-Bass.

[21] Ministère du développement social, (2011), Etude sur les associations marocaines de développement : diagnostic, analyse et perspectives (Study of Moroccan development associations: diagnosis, analysis and perspectives), Ministère du développement social, Rabat.

[22] ROCHER G. (1968), Introduction à la sociologie générale (Introduction de General Sociology), Montréal, Éditions Hurtubise H.M.H.
[23] Bauer, R. (1966), Social indicators, Cambridge Massachusetts, MIT Press.

[24] Sutter, C. (2006) La société suisse en transition : Indicateurs de changement social, Soulet, M-H. In Société en changement - Société de changement, Academic Press Fribourg, p. 111-128.

[25] Derbyshire, H. (2002), Gender Manual A practical Guide for Development Policy Makers and Practitioners, DFID, London.

[26] FRANKOVITS, A. (2006) L'approche fondée sur les droits de l'homme et le système des Nations Unies, UNESCO, Paris.

[27] UNDP, (2004) Les droits de l'Homme au PNUD : Note de Pratique, NY.

[28] Ebrahim, A., \& Rangan, K. (2010), "The Limits of Nonprofit Impact: A Contingency Framework for Measuring Social Performance." Harvard Business School Working Paper, No. 10-099, May.

[29] Kearns, K-P. (1994), "The Strategic Management of Accountability in Nonprofit Organizations: An Analytical Framework", Public Administration Review, Vol. 54, No. 2 (Mar. - Apr., 1994), pp. 185-192.

[30] TROSA, S. \& Bartoli, A. (2011), Le management par le sens au service du bien public (Management by the sense of the public good), Eres Edition. 